\section{Sorption of Pesticides by Volcanic Ash Soil from Mt. Aso in "Simulated Weathering" Experiments}

\author{
Itsusei Fujita, ${ }^{*, a, b}$ Masaaki Hirohata, ${ }^{a}$ \\ Satoshi Sakaeda, ${ }^{a}$ Tetsuya Nagamura, ${ }^{a}$ \\ Hiroshi Matsushita, ${ }^{a}$ and Ryozo Matsuoka ${ }^{a}$
}

${ }^{a}$ Subterranean water Science Department, Kumamoto prefectural Institute Health and Environmental Science, 1240-1 Kurisaki-machi, Uto-shi, Kumamoto 869-0425, Japan and ${ }^{b}$ Yatsusiro Public Health Center, 1660 Nisikata-machi, Yatsusiro-shi, Kumamoto 866-8555, Japan

(Received October 11, 2002; Accepted March 24, 2003)

We previously reported ${ }^{1,2)}$ that volcanic ash soil from Mt. Aso may affect the quality of water in the regions where volcanic ash from the present crater in Naka-dake have been deposited, and that adsorption of pesticides (Environmental standards and items requiring observation according to the Fundamentals of Environment Act) by volcanic ash soil from Mt. Aso may be affected by the water-solubility of chemicals and the kinds and number of hydrophilic functional groups at the molecular level of chemicals. The present study using "simulated weathering" (treatment with humic acid) demonstrated that the pesticides that the absorption efficiency improved by treated humic acid treated were 2,2-dichlorovinyldimethylphosphate (DDVP), 2-sec-butylphenyl methylcarbamate (BPMC), $O, O$-dimethyl $O$-4-nitro-m-tolyl phosphorothioate (MEP), Bebthiocarb, Isoxathion, 4-nitrophenyl 2,4,6trichlorophenyl ether (CNP), and deteriorated adversely in Propyzamide, Diazinon.

Key words _ _ simulated weathering, humic acid, glass column, correlation of structural activity

\section{INTRODUCTION}

We previously reported ${ }^{1,2)}$ that volcanic ash soil from Mt. Aso (ash soil) may affect the quality of water in the regions where volcanic ash from the present crater in Naka-dake has been deposited. ${ }^{1)} \mathrm{We}$ also reported that adsorption of Pesticides (Environmental standards and items requiring observation

*To whom correspondence should be addressed: Yatsusiro Public Health Center, 1660 Nisikata-machi, Yatsusiro-shi, Kumamoto 866-8555, Japan. Tel.: +81-965-32-6121 according to the Fundamentals of Environment Act) by ash soil may be affected by the water-solubility of chemicals and the kinds and number of hydrophilic functional groups at the molecular level of chemicals. ${ }^{2)}$ In the present study, we examined the changes in the adsorption of pesticides ${ }^{3)}$ listed on the Environmental standards and items requiring observation according to the Fundamentals of Environment Act by simulated weathering (simple sorption of humic acid). ${ }^{4)}$

\section{MATERIALS AND METHODS}

Reagents and Apparatus — Nitric acid and sulfuric acid of the reagent grade (Wako Pure Chem. ind., Japan) and humic acid of the highest grade (Kanto Chemicals Inc., Japan) were used. The other reagents were those used in the previous studies. ${ }^{1,2)}$

$\mathrm{C}, \mathrm{H}, \mathrm{N}$ analysis was performed using a $\mathrm{C}, \mathrm{H}, \mathrm{N}$ coder (Shimadzu Inc., Japan), and total organic carbon (TOC) analysis was performed using a TOC analyzer (Shimadzu Inc.). The other agricultural chemicals were analyzed using apparatus according to the previous studies. ${ }^{1,2)}$

The particle-shaped diameter of ash soil and the surface area and $\mathrm{pH}$ which we used were $0.25 \mathrm{~mm}$ and $11.898 \mathrm{~m}^{2} / \mathrm{g}$ and $\mathrm{pH} 6.8$.

Adsorption Experiments Using Glass Columns

The adsorption of $200 \mathrm{mg} / \mathrm{l}$ agricultural chemicals eluted through a conventional column (inner diameter, $10 \mathrm{~mm}$; length, $250 \mathrm{~mm}$ ) filled with 10 ash soil ${ }^{1,2)}$ was examined.

\section{RESULTS AND DISCUSSION}

\section{Simulated Weathering Experiments}

Weathering is generally defined as mild oxidation by the atmosphere, but pedagogically it has a broad sense and includes the sorption of organic compounds in soil by plants. In this study, we examined the oxidation with nitric acid and with a mixture of nitric acid and sulfuric acid, the sorption of $\mathrm{C}, \mathrm{H}$ and $\mathrm{O}$ to aluminum, a component of soil, using glynial reagent (sorption of organic compounds in soil) and the sorption of $\mathrm{C}, \mathrm{H}$ and $\mathrm{O}$ to the soil by heating humic acid using potassium hydroxide (sorption of organic compounds in soil).

Table $1 \mathrm{a}$ ) and $1 \mathrm{~b}$ ) show the results of $\mathrm{C}, \mathrm{H}, \mathrm{N}$ and TOC analysis ash soil treated by $24-\mathrm{hr}$ eluting of humic acid with potassium hydroxide and un- 
Table 1. Change in Organic Substance Amount in the Aso Volcanic Ash Soil by Humic Acid Treatment

\begin{tabular}{lllllr}
\hline \hline & a) & \multicolumn{2}{c}{ (wt $\%)$} & b) \\
\cline { 2 - 4 } & $\mathrm{C}$ & $\mathrm{H}$ & $\mathrm{N}$ & TOC value (mg/l) \\
\hline Untreated Aso volcanic ash soil & 0.10 & 0.20 & $<0.1$ & 88 \\
Aso volcanic ash soil treated with humic acid treatment & 0.15 & 0.13 & $<0.1$ & 410 \\
\hline Analyzed by CHN corder manufactured by Shimadzu Inc. Burning - infrared analysis. Analyzed by soil sample TOC measuring \\
system. Manufactured ShimadzuTOC-5000/SSM5000A.
\end{tabular}

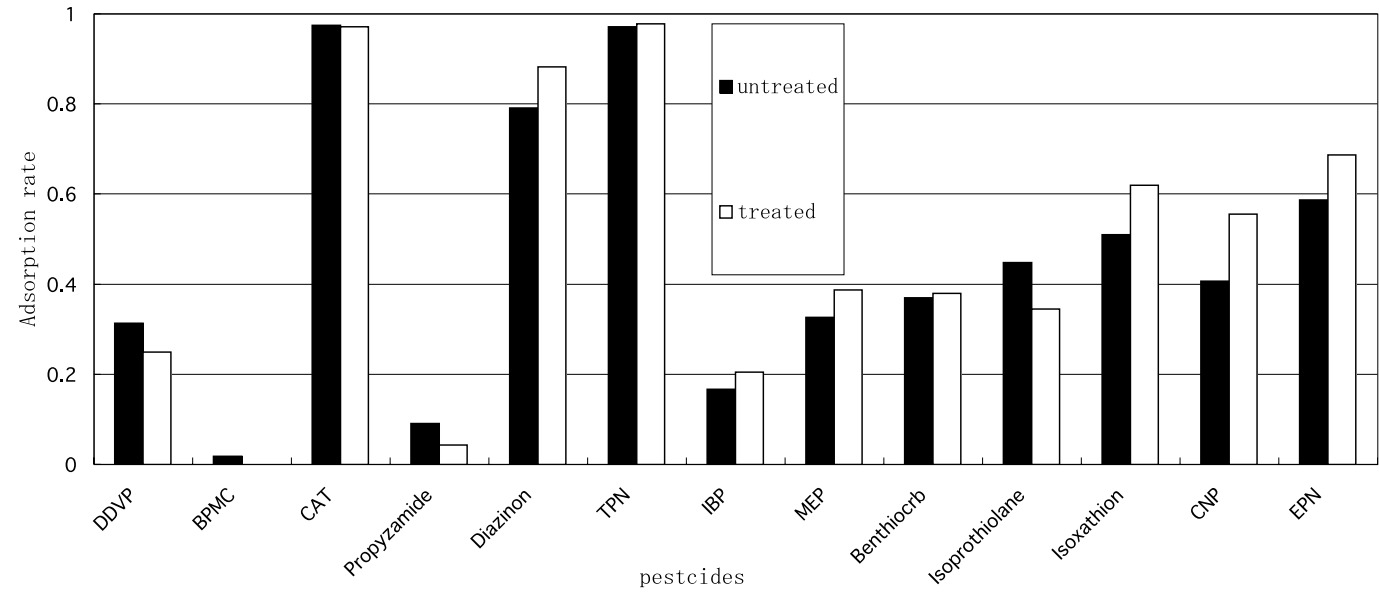

Fig. 1. Adosorption of Aso Volcanic Ash Soil Treated with Acids for Pestcide by Batch Method Adsorption rate $=(\mathrm{A}-\mathrm{B}) / \mathrm{A}$. A: concentration in solution before shaking, $\mathrm{B}$ : concentration in solution after shaking.

treated ash soil samples, respectively.

\section{Adsorption Experiments of Pesticides}

The adsorption of $200 \mathrm{ml}$ solution containing $200 \mathrm{mg} / \mathrm{l}$ pesticides listed on the Environmental standards and items requiring observation according to the Fundamentals of Environment Act was examined using $10 \mathrm{~g}$ ash soil by the batch method.

The changes in the adsorption of agricultural chemical components in ash soil treated with nitric acid and with a mixture of nitric acid and sulfuric acid were similar to those in the untreated ash soil. Figure 1 shows an example of the changes in the adsorption to ash soil treated with nitric acid.

There was no difference in the changes in the adsorption between ash soil treated with inorganic acid and untreated volcanic ash soil.

The experiments by the batch method demonstrated that the changes in the adsorption of the C-, $\mathrm{H}$ - and $\mathrm{O}-$ loaded ash soil by glynial reaction was similar to those in ash soil treated with acid.

The volcanic ash soil sample from Mt. Aso treated by 24-hr eluting of humic acid with potassium hydroxide were filled in glass columns, and subjected to adsorption experiments pesticides. ${ }^{2)}$
Figure 2a shows the results.

In parallel experiments, adsorption experiments of pesticides were performed using glass columns filled with untreated ash soil Fig. $2 b$ show the results.

In Table 1b), large changes in the level of TOC, the amount of organic carbon, are clear (increases by the treatment). It has been known that organic compounds are strongly adsorbed in soil.,5) The adsorption of pesticides in ash soil was low as shown in the previous study, but it increased by treatment with humic acid, a component of putrefied plants.

In this study, there were no changes in the adsorption of humic acid contaminants by mild oxidation (weathering in a narrow sense). However, the results suggested that adsorption of organic chemicals (pesticides with low adsorption in ash soil shown in the previous study ${ }^{2}$ ) increases by increasing organic compounds in soil (loading of organic compounds in soil by putrefaction of plants; weathering in a broad sense).

The absorption efficiency of CAT was beginning.

The pesticides that the absorption efficiency improved by treated humic acid treated were 2,2dichlorovinyldimethylphosphate (DDVP), 2-sec- 


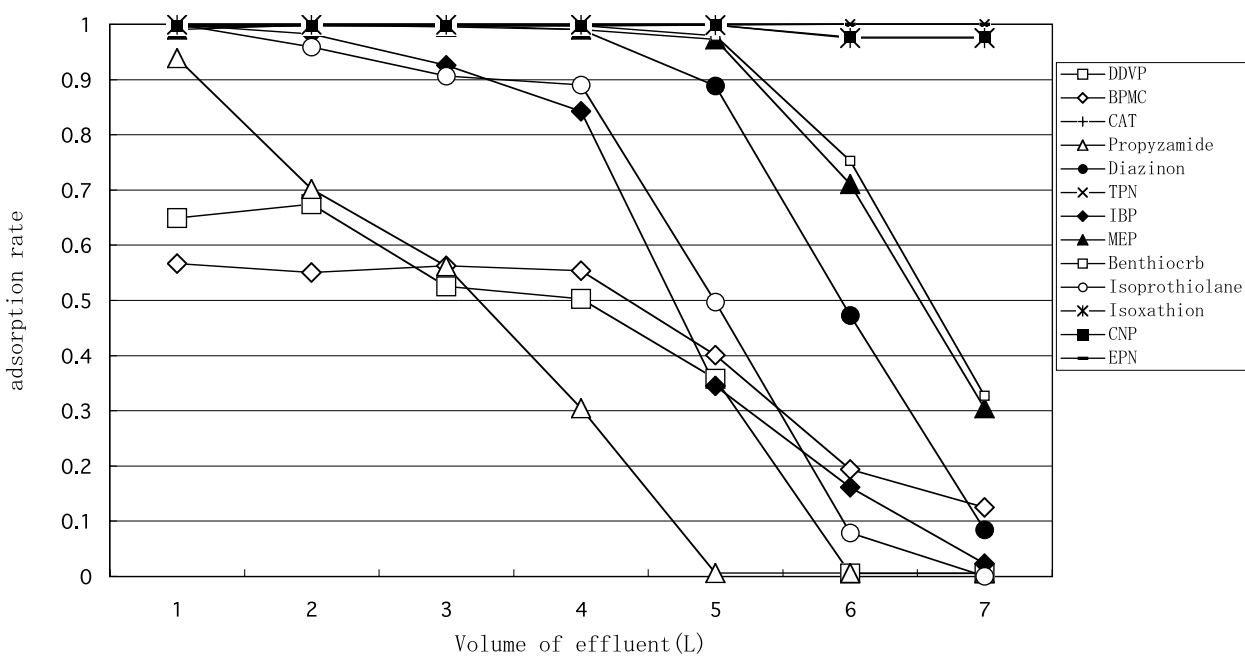

Fig. 2a. Adsorption of Aso Volcanic Ash Soil Treated with Humic Acid for Contaminated Pesticides by Column Method Adsorption rate $=(\mathrm{A}-\mathrm{B}) / \mathrm{A}$. A: concentration in solution before flowing, $\mathrm{B}$ : concentration in solution after flowing.

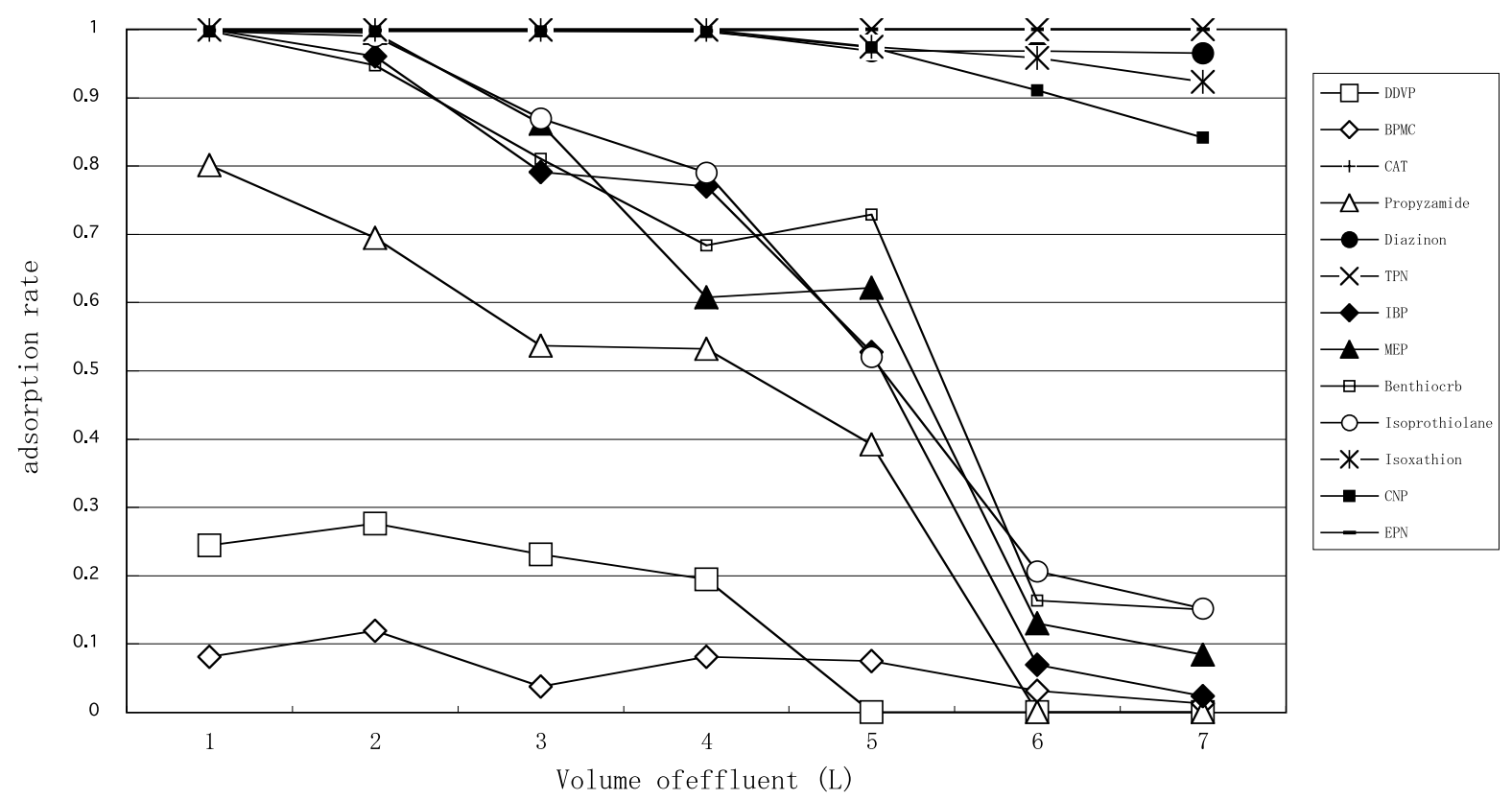

Fig. 2b. Adsorption of Untreted Aso Volcanic Ash Soil for Pesticides by Column Method Adsorption rate $=(\mathrm{A}-\mathrm{B}) / \mathrm{A}$. A: concentration in solution before flowing, $\mathrm{B}$ : concentration in solution after flowing.

butylphenyl methylcarbamate (BPMC), $O, O$-dimethyl $O$-4-nitro-m-tolyl phosphorothioate (MEP), Bebthiocarb, Isoxathion, 4-nitrophenyl 2,4,6trichlorophenyl ether (CNP), and deteriorated adversely in Propyzamide, Diazinon.

\section{REFERENCES}

1) Fujita, I., Hirohata, M., Matsuzaki, Tatsuya., Matsushita, H. and Matsuoka, R. (1998) Adsoption of Ammonium and Phosphate Ions and Components in Groundwater by Aso Volcanic Ash Soil. Japanese journal of Toxicology and Environmetal Health, 44, 386-391.

2) Fujita, I., Hirohata, M., Sakaeda, S., Nagamura, T., Matsushita, H. and Matsuoka, R. (1999) Adsorption Experiments of Organic Contaminant Compounds by Aso Volcanic Ash Soil. Tikasui gakkai, 41, 8795.

3) Nagakura, S. (ed.) (1999) Iwanami Physics and Chemistry Dictionary, Fifth edition, CD-ROM, 
Iwanami Shoten, Tokyo.

4) Shimizu, Y. and Terashima, Y. (1991) Interaction of the soil and organic pollutant in groundwater contamination. In Abstracts for the first research meeting on contamination in groundwater and its countermeasures, Kyoto, p. 104.

5) Nakano, M. (1991) Mass transfer of soil, University of Tokyo Press, Tokyo, pp. 131-146. 